\title{
Sexual Differentiation of Rat Hepatic Bile Salt Sulfotransferase Isoenzymes
}

\author{
ROBERT E. KANE, LEE J. CHEN, JOHN J. HERBST, ${ }^{1}$ AND M. MICHAEL THALER \\ Department of Pediatrics, University of Utah Medical Center, Salt Lake City, Utah 84132 [R.K., J.H.]; \\ Department of Biochemistry, University of California, Davis, California 95656 [L.C.]; Department of Pediatrics,
} University of California, San Francisco, California 94116 [M.T.]

\begin{abstract}
The mature female rat has three times the hepatic bile salt sulfotransferase (BSS) activity compared with male rats. This study examined the changes in two hepatic BSS isoenzyme activities during sexual maturation, and the role of estrogen in development of sex differences in BSS activities in mature rats. DEAE-Sephadex A-50 chromatography of hepatic cytosol from prepubescent pups revealed that more than $90 \%$ of total BSS activity was due to BSS I activity relative to BSS II, similar to postpubertal females. Sex differences in total BSS activities and the isoenzyme patterns developed after the onset of puberty at 30-35 days of age. BSS I was still the predominant isoenzyme in the adolescent female, similar to the prepubescent pup and mature female. In contrast, BSS I activity declined in adolescent males, which appeared to explain the fall in total BSS activity to only one-third of that of the female by maturity. BSS II activity was similar in both sexes at any age. Estrogen treatment of postpubertal male rats rapidly increased hepatic BSS capacity by enhancing BSS $I$ activity producing an isoenzyme pattern similar to the mature female. This rapid enhancement of BSS I by estrogen was blocked by actinomycin $D$ and puromycin. We concluded that 1) sex differences in BSS activities that develop during adolescence were in part due estrogenmaintaining BSS I activity in females and 2) estrogen regulates the synthesis of BSS I at a translational (or pretranslational) level. (Pediatr Res 24: 247-253, 1988)
\end{abstract}

\section{Abbreviation}

PAPS, 3'-phosphoadenosine-5' -phosphosulfate EDAC, 1-ethyl-3-(-3-dimethyl amine propyl) carbodiimide

Sulfation by hepatic bile salt sulfotransferases is an important determinant of the metabolic fate and physiologic effects of monohydroxy bile acids in developing and mature mammals (1, 2 ). Lithocholate, which originates from the bacterial dehydroxylation of chenodeoxycholate in the intestines, causes cholestasis under various experimental conditions in animals (3). Hepatic sulfation of lithocholate and other monohydroxy bile acids increases the fecal and urinary excretion of these potential hepatotoxins preventing their accumulation in the enterohepatic circulation $(1,2)$.

Received September 14, 1987; accepted April 18, 1988

Correspondence and reprint requests Robert E. Kane, M.D., Pediatric Gastroenterology, St. Louis University Medical School, 1465 South Grand Boulevard, St Louis, MO 63104.

Supported by National Institute of Health Grants HD03148 and AM25970 and a University of Utah Biomedical Research Award

${ }^{1}$ Present address: Department of Pediatrics, Louisiana State University, Shreveport, LA 71130.
In utero, hepatic sulfation of maternal-derived lithocholate and fetal monohydroxy bile acids results in sequestration of these potential hepatotoxins in the distal intestines in meconium (4). It is suggested that immaturity of hepatic sulfation by the fetal and newborn liver explains the progressive hepatic necrosis and bile duct injury observed in the offspring during maternal bile acid feeding in rodents $(5,6)$ and primates $(7,8)$ and may play a role in cholestatic liver disease in infants (9).

Age-related changes in bile salt sulfotransferase activity are observed during development in the rat; the sulfotransferase activity is very low in the fetal and newborn pups, but rises rapidly in the first weeks of life until a peak of activity at the time of weaning $(6,10)$. Sex-related differences in activity develop after the onset of puberty, resulting in 3-fold greater sulfotransferase activity in mature females compared with males $(6,10-$ 12).

The presence or absence of ovarian estrogens appear to be a major determinant in the sex differences in bile salt sulfotransferase activities in postpubertal rats. Oophorectomy results in a decline in sulfation capacity in mature females, whereas treatment of males with ethinyl estradiol or estradiol benzoate for $10-42$ days enhances sulfotransferase activity (10-14). The estrogen stimulation of bile salt sulfotransferase activity occurs with doses that do not cause cholestasis, and this enhanced activity correlates with the increased excretion of bile salt sulfates in bile $(11,15)$.

We have identified two bile salt sulfotransferase isoenzymes (I and II) in rat hepatic cytosol that have the same apparent molecular weight, but different isoelectric points, substrate activities, and sex distribution (12). Bile salt sulfotransferase I activity is enhanced by estrogen, and contributes $90 \%$ of total sulfotransferase capacity in females versus about $30 \%$ in males (12). Bile salt sulfotransferase II, the predominate isoenzyme in males, has similar activity in both sexes and is not apparently influenced by gonadal hormones.

Collins et al. (16) recently used a monoclonal antibody to purify and characterize a bile salt sulfotransferase in rat hepatic cytosol which contributes $90 \%$ of sulfation capacity in females and $40-50 \%$ of activity in males. This purified bile salt sulfotransferase exhibits activity for hydroxysteroids as well as bile acids (16), and its activity is regulated by estrogens and androgens (15).

In this study, we examined the pattern of sexual differentiation of two bile salt sulfotransferase isoenzyme activities during development, and the mechanism of estrogen enhancement of one of the isoenzymes in mature males.

\section{MATERIALS}

Nonradioactive and radioactive PAPS were prepared using Baker's yeast as described previously (12). Additional nonradioactive PAPS was purchased from P-L. Biochemical Inc., Milwaukee, WI. Bile acids were purchased from Calbiochem (La 
Jolla, CA), except $3 \beta$-hydroxy-5-cholenoate (Steraloids, Wilton, $\mathrm{NH}$ ). Other chemicals used were Sepharose 4B and DEAESephadex A-50 (Pharmacia, Piscataway, NJ) EDAC (Sigma Chemical Co., St. Louis, MO). Glycolithocholate and other bile acids were bound to Sepharose 4B using EDAC as previously described in detail (17).

\section{METHODS}

Liver cytosol was prepared after the livers were excised, weighed, and quickly frozen at $-20^{\circ} \mathrm{C}$. The next day, $4 \mathrm{~g}$ of minced liver was then homogenized in $20 \mathrm{ml}$ of ice-cold $0.25 \mathrm{M}$ sucrose containing $5 \mathrm{mM}$ Tris- $\mathrm{HCl}(\mathrm{pH} 7.5), 1 \mathrm{mM}$ EDTA, and $10 \mathrm{mM}$ mercaptoethanol using a Potter-Elvehjem homogenizer and a Teflon pestle. The homogenate was centrifuged at 105,000 $\times \mathrm{g}$ for $60 \mathrm{~min}$ at $4^{\circ} \mathrm{C}$ and the clear supernatant removed leaving the lipid layer undisturbed. Bile salt sulfotransferase activity was assayed using glycolithocholate bound to Sepharose 4B as substrate with $\left[{ }^{35}\right.$ S]PAPS (mixed with cold PAPS) as the sulfate donor as previously described (17). The protein concentration was estimated by the method of Lowry et al. (18) with bovine serum albumin as standard. The enzyme sp. act. was expressed as pmol of glycolithocholate sulfate/mg protein $/$ min (mean \pm $\mathrm{SE})$. When the assay was performed using $3 \beta$-hydroxy-5-cholenoate and other bile acids, the substrate was bound to Sepharose$4 \mathrm{~B}$ as previously described for glycolithocholate (17). Sulfotransferase activity in DEAE-Sephadex A-50 chromatograms was expressed as ng glycolithocholate sulfate $/ \mathrm{ml} / \mathrm{h}$.

A total of $4 \mathrm{ml}$ of rat liver cytosol, $20 \%$ homogenate $(\mathrm{g} / 100$ $\mathrm{ml})$ was applied to a column $(1.8 \times 2 \mathrm{~cm})$ of DEAE-Sephadex $\mathrm{A}-50$ at $5^{\circ} \mathrm{C}$. The column was equilibrated with a $0.25 \mathrm{M}$ sucrose solution containing $5 \mathrm{mM}$ Tris ( $\mathrm{pH} 7.5$ ), $1 \mathrm{mM}$ EDTA, and 10 $\mathrm{mM}$ 2-mercaptoethanol, and eluted with a $0.3 \mathrm{M} \mathrm{NaCl}$ linear gradient. Fractions of $5 \mathrm{ml}$ were collected, and bile salt sulfotransferase activity assayed using $\left[{ }^{35}\right.$ S]PAPS with an activity of $8.0 \times$ $10^{5} \mathrm{dpm} / 20 \mu \mathrm{l}$. Protein concentration of column fractions was estimated by measuring absorbance at $280 \mathrm{~nm}$. Ten fractions with the highest bile salt sulfotransferase I and II activities were pooled and concentrated by ultrafiltration (Diaflo PM10, Amicon Co., Lexington, MA)

\section{EXPERIMENTAL ANIMALS}

Spraque-Dawley rats (Simonson Breeding Laboratories, Gilroy, CA) were used in all experiments. All procedures were approved by the University Animal Care Committee. When they died the rats were anesthetized with pentobarbital and killed by exsanguination.

Developmental studies. Dated, pregnant females were killed on day 15-16, 18-19, and 21-22 of gestation to obtain fetal and maternal livers. The liver tissue of two fetuses were pooled for assay of total sulfotransferase activity, and eight to 10 fetal livers pooled to obtain sufficient cytosol for isoenzyme chromatograms. Other pregnant rats were allowed to deliver and six to 10 pups of each sex killed at 7, 14, 21, 28, 35, 42, and 56 days of age. Mothers and pups after weaning were maintained on standard rat food with water ad libitum.

Estrogen treatment. Mature male rats (250-275 g) were injected daily with $17 \beta$-estradiol, ethinyl estradiol, or estradiol benzoate dissolved in $0.2 \mathrm{ml}$ propylene glycol as vehicle, or vehicle alone for controls. All injections were made between 0900-1000 $\mathrm{h}$ and rats killed after specified number of days.

Effect of actinomycin D and puromycin. Estrogen-treated males were administered either actinomycin D or puromycin to determine at what level estrogens regulate the synthesis of bile salt sulfotransferase I synthesis. Actinomycin D prevents messenger RNA transcription (19), whereas puromycin inhibits protein translation (20). Mature male rats were treated with either 1 ) ethinyl estradiol $80 \mu \mathrm{g} / 100 \mathrm{~g}$ body weight/day subcutaneously every morning at $1000 \mathrm{~h} ; 2$ ) actinomycin D $0.01 \mathrm{mg}$ intraperi- toneally at 0900 and $2100 \mathrm{~h} ; 3$ ) both actinomycin D and ethinyl estradiol at the same times as groups a and b; or 4) controls injected with propylene glycol.

In another set of experiments, male rats were treated with 1 ) ethinyl estradiol $80 \mu \mathrm{g} / 100 \mathrm{~g}$ body weight/day subcutaneously; 2) puromycin $4 \mathrm{mg}$ intraperitoneally at 0800,1500 , and $2200 \mathrm{~h}$; 3 ) both ethinyl estradiol and puromycin as in 1) and 2); and 4) controls injected with propylene glycol. Rats were treated for 2 days and liver tissue removed between 0900-1000 h for enzyme assays and chromatography.

Mature female rats $(150-175 \mathrm{~g})$ were treated with ethinyl estradiol $(50 \mu \mathrm{g} / 100 \mathrm{~g}$ body weight/dose) or vehicle subcutaneously daily at $0900 \mathrm{~h}$ and killed to obtain liver tissue on the morning of the 8th day. Prepubertal pups (13 days old, $28-30 \mathrm{~g}$ body weight) and postpubertal rats (30 days old, 90-100 g body weight) of both sexes were injected with ethinyl estradiol $(50 \mu \mathrm{g} /$ $\mathrm{kg}$ body weight) or carrier subcutaneously daily at $0900 \mathrm{~h}$ and killed after 5 days of treatment. The Student's unpaired $t$ test was used for statistical analysis.

\section{RESULTS}

Sulfotransferase activity during sexual differentiation. Bile salt sulfotransferase activity toward glycolithocholate was first detectable in the fetus at 18-19 days gestation (Fig. 1). The nearterm (20- to 21-day gestation) and newborn pup sulfotransferase activity was only $6-10 \%$ of maternal enzyme activity, and less than one-third that of the mature male. The total sulfotransferase activity rose from birth during the first $3 \mathrm{wk}$ until a peak at the time of weaning. Thereafter, sulfotransferase activity in both sexes declined until the onset of puberty at 28-35 days of life, when sex-related differences in activity become apparent. The sulfotransferase capacity in the female remained relatively constant during adolescence (28-56 days) and adulthood. In contrast, the sulfotransferase capacity in males gradually declined during adolescence to one-third of the activity of mature females by 56 days of age.

Isoenzyme pattern during sexual differentiation. Two bile salt sulfotransferase isoenzymes were identified using DEAE-Sephadex A-50 ion-exchange chromatography of rat hepatic cytosol except in the very immature liver. Cytosols from several pups were pooled because the total sulfotransferase capacity in fetal and newborn livers was relatively low. Only one sulfotransferase activity was clearly identified in fetal and newborn pups eluting at $0.05 \mathrm{M} \mathrm{NaCl}$ (Fig. $2 A$ ), which corresponded with bile salt sulfotransferase I in more mature rat (Fig. $3 C$ and $F$ ). Total sulfotransferase activity increased several-fold in the first week of life (Table 1) and a bile salt sulfotransferase II moiety eluting with $0.14 \mathrm{M} \mathrm{NaCl}$ was clearly identified by 7 days of life (Fig. $2 C)$.

The glycolithocholate sulfotransferase isoenzyme patterns from 7-28 days of life in male and female rats were similar, with $70-80 \%$ of total enzyme activity present as sulfotransferase I, and $20-30 \%$ of total activity due to sulfotransferase II (Fig. $2 \mathrm{C}$ $F$ ). Sex differences in the isoenzyme patterns became apparent after the onset of puberty at 30-35 days of age. In the female rat (Fig. $3 A$ and $B$ ), the isoenzyme pattern during adolescence remained similar to the 7-to 28-day pups of both sexes, and was similar to that of the mature female (Fig. $3 C$ ). In contrast, sulfotransferase I activity declined progressively in adolescent males (Fig. $3 D-F$ ) similar to the decline in total sulfotransferase capacity (Fig. 1). As a result of the decline in bile salt sulfotransferase I activity during adolescence, this isoenzyme contributed only about $30 \%$ of total activity in the mature male (Fig. $3 F$ ) with the predominant activity contributed by sulfotransferase II. There was a $82-86 \%$ recovery of enzyme activity in all chromatograms.

Ontogeny of estrogen enhancement. Prepubertal rats of both sexes were treated with ethinyl estradiol $(50 \mu \mathrm{g} / 100 \mathrm{~g}$ body weight/day) from 13-18 days of age, and another group from 
$30-35$ days of life. No significant differences in sulfotransferase activity occurred in rats of either sex treated from days 13-18 $(61.2 \pm 2.4$ versus $57.1 \pm 2.5 \mathrm{U}$ for controls) or females treated from $30-35$ days $(33.5 \pm 4.8$ versus $35.7 \pm 6.2 \mathrm{U}$ for controls). However, male rats treated from age 30 to 35 days with ethinyl estradiol showed a modest rise in sulfotransferase activity (35.9 \pm 3.0 versus $27.3 \pm 3.7 \mathrm{U}$ for controls, $p<0.05$ ).

Treatment of intact mature females with ethinyl estradiol (125 $\mu \mathrm{g} / 100 \mathrm{~g}$ body weight/day for 7 days) did not significantly effect the total hepatic sulfotransferase activity $(33.5 \pm 4.8$ versus 35.7 \pm 2 for controls) nor change the isoenzyme pattern. The sulfotransferase activity and isoenzyme pattern of mature females was

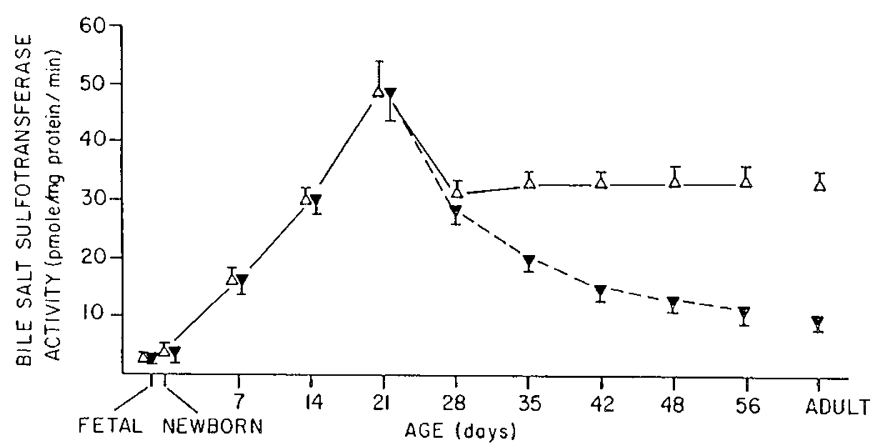

Fig. 1. Bile salt sulfotransferase activity during sexual maturation (glycolithocholate as substrate). Data points represent mean $\pm \mathrm{SE}$ of five males $(\boldsymbol{\nabla})$ or females $(\triangle)$. Cytosol from two livers was pooled for fetal (18-19 days gestation) and newborn ( $<1$ day old) pups to provide an adequate sample. also not effected by the increased endogenous estrogens during pregnancy (Table 1).

In contrast, ethinyl estradiol treatment $(50 \mu \mathrm{g} / 100 \mathrm{~g}$ body weight/day) of mature males for only 3 days more than doubled the sulfotransferase capacity for monohydroxy and dihydroxy bile acids (Table 1). The rapid enhancement in estrogen-treated males resulted in sulfotransferase activity that was intermediate between control males and that of mature pregnant and nonpregnant females.

Comparison of estrogen preparations. Three estrogen preparations previously shown to enhance bile salt sulfotransferase activity with a variety of doses over 10-42 days (11-16) were compared for their ability to rapidly enhance the sulfation capacity of males (Fig. 4). 17 $\beta$-estradiol was used because it is the most potent naturally occurring estrogen. Ethinyl estradiol was compared because addition of the ethinyl group inhibits the hepatic catabolism of $17 \beta$-estradiol prolonging its metabolic effects on the liver. Conjugation with benzoate also prolongs the catabolism of $17 \beta$-estradiol by increasing its lipid solubility so that is slowly released from adipose tissue after subcutaneous injection. No significant effect was noted after 1 day of treatment with all three preparations, but ethinyl estradiol and $17 \beta$-estradiol enhanced sulfotransferase capacities 137 and $202 \%$ of controls after 2 days and 199 and $260 \%$ after 3 days of treatment, respectively. In contrast, estradiol benzoate treatment for up to 3 days minimally influenced sulfotransferase activity after up to 3 days of treatment.

The magnitude of the rapid enhancement of sulfotransferase activity by $17 \beta$-estradiol and ethinyl estradiol treatment increased proportionate to the estrogen dose (Table 2).

The influence of estrogen on each of the sulfotransferase isoenzyme activities was determined after chromatographic sep-
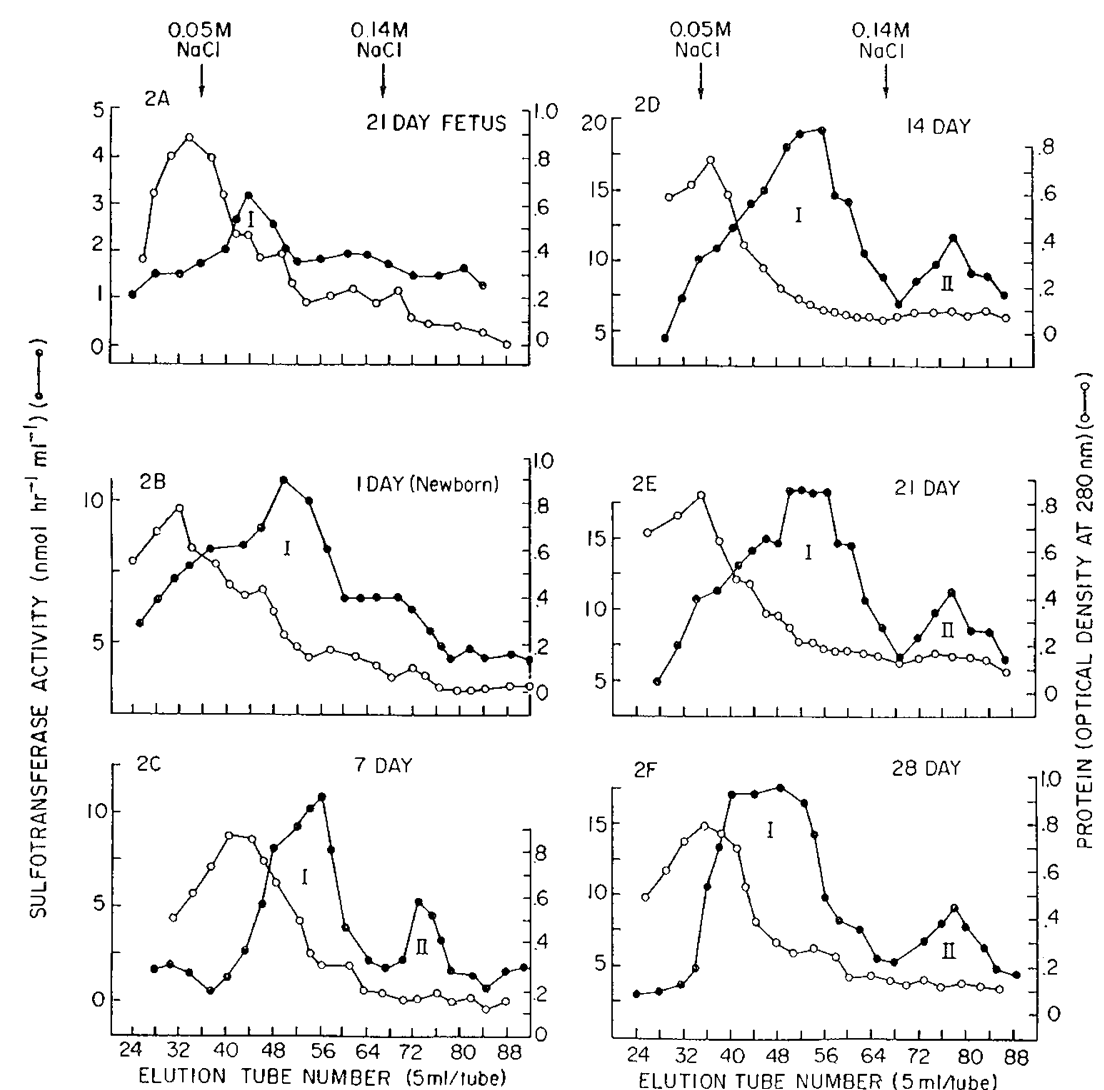

Fig. 2. DEAE-Sephadex A-50 chromatography of bile salt sulfotransferase isoenzymes in developing pups from fetus until the onset of puberty at 28 days of age. A total of $4 \mathrm{ml}$ of hepatic cytosol was applied to a column $(1.8 \times 22 \mathrm{~cm})$ with a 0 to $0.3 \mathrm{M} \mathrm{NaCl}$ gradient. Five ml fractions were collected and assayed for enzyme activity $(\bullet)$. Incubation time varied from $30 \mathrm{~min}$ for fetus to $15 \mathrm{~min}$ for 14 - to 28-day-old pups. Protein concentration was measured by absorbance at $280 \mathrm{~mm}(\mathrm{O})$. The 7- to 28-day-old isoenzyme profiles were representative of chromatograms of both sexes; fetal and newborn livers were pooled to provide adequate samples. 


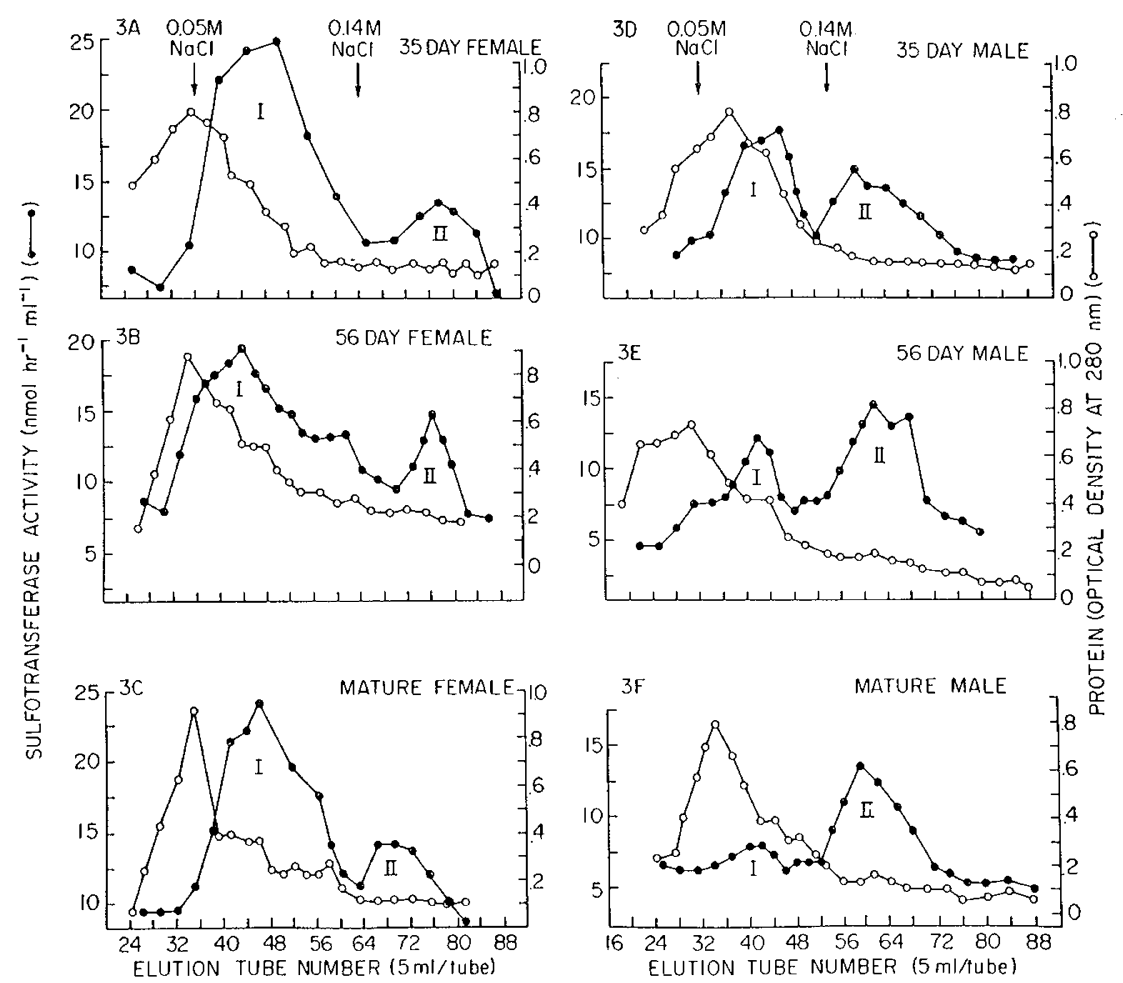

Fig. 3. DEAE-Sephadex A-50 chromatography of bile salt sulfotransferase isoenzymes in postpubertal male and female rats. Assay conditions as in Figure 2 except incubation time of $15 \mathrm{~min}$ for mature females and $20 \mathrm{~min}$ for mature males.

Table 1. Effect of estrogen on bile salt sulfotransferase activity (pmol/mg.protein/min, mean $\pm S E)^{*}$

\begin{tabular}{|c|c|c|c|c|}
\hline Substrate & Mature female & Pregnant female & Mature male & $\begin{array}{c}\text { Estradiol-treated } \\
\text { male }\end{array}$ \\
\hline Glycolithocholate & $34.8 \pm 2.3$ & $35.3 \pm 2.6$ & $9.7 \pm 1.1$ & $22.0 \pm 3.7 \dagger$ \\
\hline Taurolithocholate & $33.0 \pm 2.7$ & $36.4 \pm 2.5$ & $10.1 \pm 1.2$ & $21.5 \pm 2.8 \dagger$ \\
\hline $3 \beta$-hydroxy-5-cholenoate & $80.6 \pm 7.8$ & $95.0 \pm 5.5$ & $16.3 \pm 1.5$ & $33.8 \pm 4.3 \dagger$ \\
\hline Glycochenodeoxycholate & $6.9 \pm 1.3$ & $7.3 \pm 0.8$ & $2.6 \pm 0.5$ & $5.4 \pm 1.0 \dagger$ \\
\hline Taurochenodeoxycholate & $6.6 \pm 1.0$ & $6.8 \pm 1.0$ & $2.5 \pm 0.4$ & $5.1 \pm 0.8 \dagger$ \\
\hline
\end{tabular}

* Bile salt sulfotransferase activities of mature females $(225-250 \mathrm{~g})$ and (250-336 g) pregnant females (20-21 days gestation) compared with mature males $(250-275 \mathrm{~g})$ and ethinyl estradiol-treated males $(50 \mu \mathrm{g} / 100 \mathrm{~g}$ body weight/day for 3 days). $n=5 /$ group.

$\dagger p<0.05$ versus mature males.

aration and ultrafiltration (Table 3 ). 17 $\beta$-estradiol treatment of male rats for 2 days doubled the bile salt sulfotransferase I activity when compared to controls, but did not appear to influence sulfotransferase II activity.

Mechanism of estrogen enhancement of sulfotransferase I. Treatment of male rats with ethinyl estradiol daily for 2 days enhanced hepatic bile salt sulfotransferase capacity $188 \%$ compared with controls (Table $4 A$ ) due to enhanced sulfotransferase I activity (Fig. 5). Administration of actinomycin D, which prevents messenger RNA transcription, did not significantly effect the sulfotransferase capacity or chromatographic pattern when given alone. However, actinomycin $\mathrm{D}$ administration to estrogen-treated male rats prevented $67 \%$ of the increase in total sulfation capacity (Table $4 A$ ) and sulfotransferase I activity (Fig. 5) anticipated by estrogen treatment alone.

Similarly, puromycin, which inhibits protein translation, completely blocked the anticipated increase in sulfotransferase capacity (Table $4 B$ ), and enhancement of sulfotransferase I activity (Fig. 5) observed by estrogen treatment alone. There was a trend toward a loss in body weight and liver weight in the groups treated with actinomycin $\mathrm{D}$ and puromycin.

\section{DISCUSSION}

The results of this study clarified several aspects of the developmental changes and sexual differentiation of hepatic bile salt sulfotransferase activities. The bile salt sulfotransferase activity in the fetal and newborn liver was low with only one isoenzyme activity (sulfotransferase I) clearly identifiable. Although relatively low, this hepatic sulfotransferase activity in the mammalian liver is presumably responsible for the large quantities of monohydroxy bile acid sulfates found sequestered in fetal meconium $(2,4)$. The 10 -fold greater sulfotransferase activity in the maternal liver could have physiologic importance protecting the maternal and fetal liver by reducing the maternal pool of lithocholate and other monohydroxy bile acids through efficient fecal excretion. The rapid rise in sulfotransferase isoenzyme activities from birth to the time of weaning parallels the increase in total bile acid pool in the immature rat (21) and maturation of the enterohepatic circulation (22). This rapid postnatal rise in bile salt isoenzyme activities was similar to the rise in steroid and phenol sulfotransferase activities during development $(23,24)$.

Sex differences in bile salt sulfotransferase activities and the 


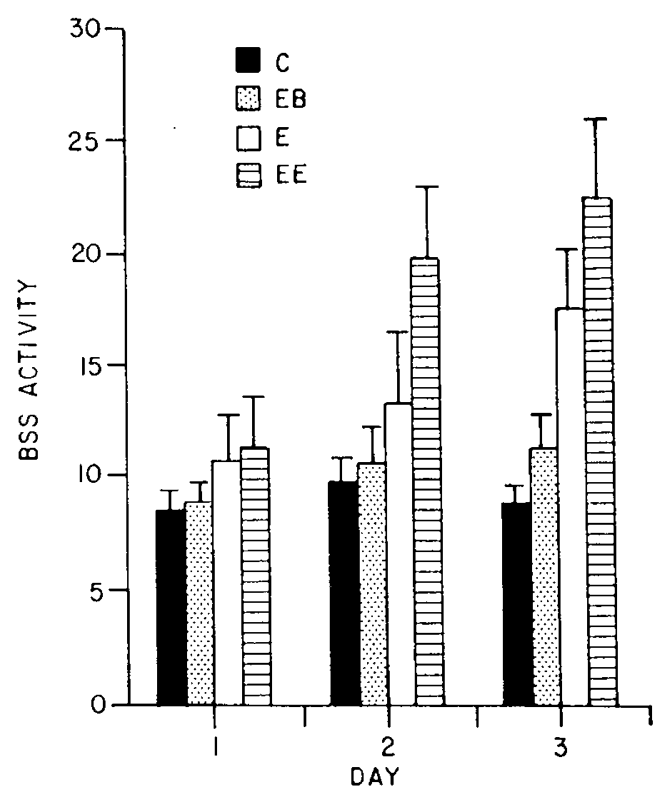

Fig. 4. Bile salt sulfotransferase activity of mature male rats treated for 1,2 , or 3 days with $50 \mu \mathrm{g} / 100 \mathrm{~g}$ body weight/day of estradiol benzoate $(E B), 17 \beta$-estradiol $(E)$, or ethinyl estradiol $(E E)$ compared with controls (C) $($ mean $\pm \mathrm{SE}, n=4)$.

Table 2. Effect of different estrogen preparations on bile salt sulfotransferase (BSS) activities*

\begin{tabular}{lcc}
\hline Treatment & $\begin{array}{c}\text { Dose } \\
(\mu \mathrm{g} / 100 \\
\text { body wt/day) }\end{array}$ & $\begin{array}{c}\text { BSS activity } \\
(\mathrm{pmol} / \mathrm{mg} \cdot \mathrm{protein} / \mathrm{min}) \\
(\mathrm{mean} \pm \mathrm{SE})\end{array}$ \\
\hline Control & 12.5 & $10.2 \pm 0.7$ \\
& 50 & $8.7 \pm 0.6$ \\
& 100 & $9.7 \pm 1.0$ \\
Estradiol benzoate & 12.5 & $11.4 \pm 0.9$ \\
& 50 & $11.3 \pm 1.6$ \\
17ק-estradiol & 12.5 & $15.8 \pm 2.7$ \\
& 50 & $17.5 \pm 2.5 \dagger$ \\
& 100 & $21.6 \pm 3.5 \dagger$ \\
Ethinyl estradiol & 12.5 & $18.2 \pm 2.7 \ddagger$ \\
& 50 & $22.4 \pm 3.1 \ddagger \S$ \\
& 100 & $22.0 \pm 3.7 \ddagger$ \\
\hline
\end{tabular}

* Male rats $(n=5)$ were injected with specified doses of an estrogen preparation subcutaneously daily $(0900-1000 \mathrm{~h})$ and bile salt sulfotransferase activity determined $24 \mathrm{~h}$ after the second dose.

$\dagger p<0.05$ compared to controls.

$\ddagger p<0.01$ compared to controls.

$\S p<0.05$ versus estradiol benzoate. isoenzyme patterns first became apparent during early adolescence (30-35 days of age), similar to the ontogeny of sex differences in other hepatic enzymes $(25,26)$. Sex differences in steroid hormone metabolism in the rat are not seen before 30 days of age and are not completed until 42 days of age (27-29). The sulfotransferase activity in prepubescent pups was not influenced by estrogen treatment, a phenomenon observed with other estrogen-inducible hepatic enzymes and proteins (23-24). This suggested that the predominance of sulfotransferase I activity in prepubertal pups resembling the mature "female" enzyme pattern was not due to the influence of gonadal hormones.

The sex differences in total sulfotransferase capacities that developed during adolescence appeared to be due to a decline in sulfotransferase I in males. This decline in activity may be at least in part because testicular androgens suppress bile salt sulfotransferase activity in males $(15,30)$. Daily estrogen treatment of adolescent males until maturity prevents most of this decline (12), suggesting the fall in sulfotransferase I activity in males during adolescence was at least in part from lack of enhancement by ovarian estrogens as in the female, as well as the suppressive influence of testicular androgens on male bile salt sulfotransferase activity $(15,30)$.

In contrast to the estrogen responsiveness of males and oophorectomized females $(10-15)$, the sulfotransferase capacity of the postpubertal intact female was not effected by ethinyl estradiol treatment or increased endogenous estrogens during pregnancy, a phenomenon also observed for other hepatic enzymes that are estrogen-sensitive in male rats $(23,24)$. This suggested

Table 4. Effect of actinomycin D or puromycin or ethinyl estradiol enhancement of bile salt sulfotransferase activity*

\begin{tabular}{lccc}
\hline \multicolumn{1}{c}{ Treatment groups } & Body wt & Liver wt & Enzyme activity \\
\hline A. Control & $294 \pm 15$ & $10.6 \pm 0.8$ & $9.7 \pm 2.4$ \\
$\quad$ Ethinyl estradiol & $292 \pm 23$ & $11.0 \pm 0.9$ & $18.2 \pm 2.7 \dagger$ \\
Actinomycin D & $280 \pm 24$ & $8.0 \pm 1.8$ & $10.8 \pm 1.4$ \\
$\quad$ Ethinyl estradiol and & $285 \pm 8$ & $8.8 \pm 1.0$ & $12.5 \pm 2.3$ \\
$\quad$ actinomycin D & & & \\
B. Control & $229 \pm 7$ & $9.7 \pm 2.5$ & $9.1 \pm 1.4$ \\
$\quad$ Ethinyl estradiol & $225 \pm 7$ & $9.2 \pm 0.8$ & $17.2 \pm 2.9 \dagger$ \\
$\quad \begin{array}{l}\text { Puromycin } \\
\text { Ethinyl estradiol and }\end{array}$ & $215 \pm 20$ & $8.5 \pm 1.2$ & $8.6 \pm 1.4$ \\
$\quad$ actinomycin D & & $9.6 \pm 1.6$ & $8.7 \pm 1.3$ \\
\hline
\end{tabular}

* Control groups were injected with $1 \mathrm{ml}$ of $0.9 \% \mathrm{NaCl}$ intraperitoneally daily. Estrogen treatment groups were treated with $50 \mu \mathrm{g} / 100 \mathrm{~g}$ body weight/day ethinyl estradiol subcutaneously every morning at 1000 h. Actinomycin-treated rats received $0.01 \mathrm{mg}$ actinomycin D intraperitoneally at 0900 and $2100 \mathrm{~h}$ for 2 days. Puromycin-treated rats received $4 \mathrm{mg}$ puromycin intraperitoneally at 0800,1500 , and $2200 \mathrm{~h}$ for 2 days. Weight expressed in $\mathrm{g}$, enzyme activity expressed as $\mathrm{pmol} / \mathrm{mg} \cdot$ protein/ min (mean $\pm \mathrm{SE}$ ) of five rats per group.

$\dagger p<0.05$ versus controls.

Table 3. Effect of $17 \beta$-estradiol treatment on bile salt sulfotransferase (BSS) isoenzymes $(\mathrm{pmol} / \mathrm{mg} \cdot \mathrm{protein} / \mathrm{min}, \mathrm{mean} \pm S E, n=5)^{*}$

\begin{tabular}{lcccrrr}
\hline & \multicolumn{2}{c}{ BSS I } & & \multicolumn{2}{c}{ BSS II } \\
\cline { 2 - 3 } \cline { 5 - 6 } Substrate & Male control & Estradiol treated & & Male control & Estradiol treated \\
\hline Glycolithocholate & $28.1 \pm 2.1$ & $55.3 \pm 4.4 \dagger$ & & $19.1 \pm 2.4$ & $21.4 \pm 2.1$ \\
3 $\beta$-OH-5-cholenoate & $47.0 \pm 9.1$ & $92.4 \pm 8.7 \dagger$ & & $1.5 \pm 0.5$ & $0.9 \pm 0.2$ & $8.8 \pm 1.3$ \\
Glycochenodeoxycholate & $7.2 \pm 1.2$ & $15.0 \pm 2.2 \dagger$ & & $8.2 \pm 1.7$ & \\
\hline
\end{tabular}

* Male rats were treated with $17 \beta$-estradiol $(100 \mu \mathrm{g} / 100 \mathrm{~g}$ body weight/day) for 2 days. The isoenzymes were separated by DEAE-Sephadex A-50 ion-exchange chromatography, and fractions with highest isoenzyme activity partially purified by ultrafiltration before substrate activities were determined.

$\dagger p<0.05$ versus controls. 

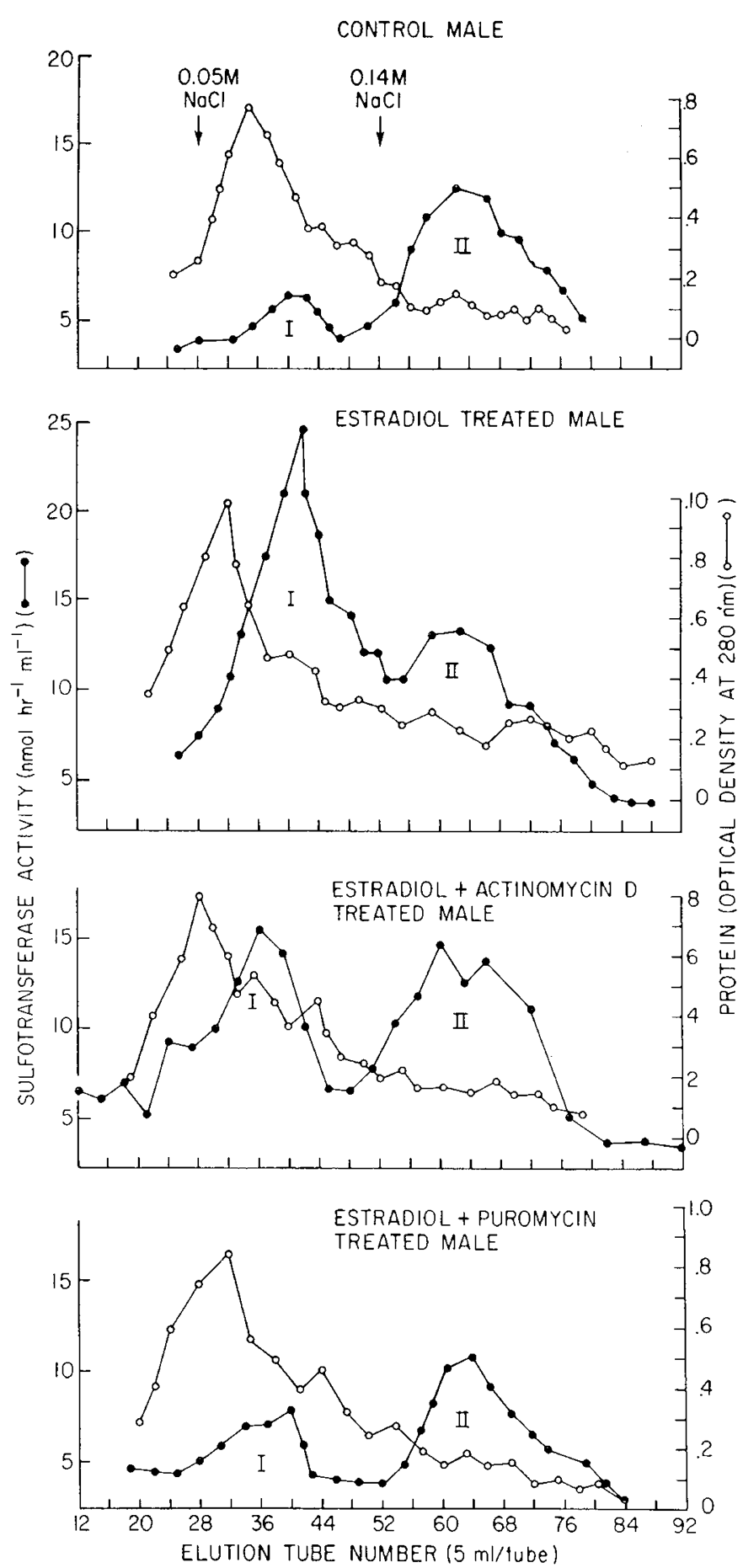

Fig. 5. DEAE-Sephadex A-50 chromatography of bile salt sulfotransferase capacities of male rats treated with ethinyl estradiol alone and ethinyl estradiol in combination with either actinomycin D or puromycin, compared with controls. Details of treatment in Table 4. Chromatography conditions as Figure 2.

that sulfotransferase I activity in the intact mature female was maximally enhanced by ovarian estrogens and cannot be further enhanced by increased endogenous or exogenous estrogens.

Estrogen enhanced bile salt sulfotransferase activity after only 2 days of treatment, which was much more rapid than previous studies using smaller daily doses for 1-4 wk (10-15). This rapid enhancement of sulfotransferase activity by estrogen was blocked by actinomycin $\mathrm{D}$ and puromycin. Actinomycin $\mathrm{D}$ complexes with guanine residues of DNA inhibiting DNA transcription (19). Puromycin, a structural analog of aminoacyl-RNA, prevents translation of RNA into polypeptide sequences resulting in the production of incomplete proteins (20). The results suggested, therefore, that estrogen primarily influenced hepatic bile salt sulfotransferase activity by regulating bile salt sulfotransferase I synthesis at a translational or pretranslational step.

A number of natural and synthetic estrogen preparations can enhance hepatic bile salt sulfotransferase activity, including nonsteroidal estrogen agonists (20). Both ethinyl estradiol and $17 \beta$ estradiol rapidly enhanced bile salt sulfotransferase I synthesis, but not estradiol benzoate. Estradiol benzoate enhances bile salt sulfotransferase activity in males after $2-6$ wk of treatment $(5$, 6 ), but had minimal effect during short-term therapy. The diminished rapid response when $17 \beta$-estradiol was conjugated with benzoate could be related to its increased lipid solubility and slower release systemically in adipose tissue after subcutaneous injection (30). Thus, the ability of exogenous estrogens to alter hepatic bile salt sulfotransferase activities during short-term treatment was dependent not only on the dose, but also the estrogen preparation.

Steroid hormones can effect hepatic metabolism by several mechanisms; one major influence is the regulation of gene expression mediated through specific cytotoplasmic hormone receptors, resulting in activation of selected sets of responsive genes (32). According to current theory, the steroid hormonereceptor complex formed in the cytoplasm translocates to the nucleus where it regulates the transcription of specific messenger RNA's coding for certain proteins (33).

Another potential influence of steroid hormones is intrahepatic cholestasis induced by estrogens in rats and humans (34-38). It is unlikely that cholestasis is the mechanism of estrogen enhancement of bile salt sulfotransferase I activity because doses 10-100 times those used in this study are necessary to induce acute cholestasis (34-38). Doses of estrogen two to three times those used in this study enhance bile salt sulfotransferase activity and the excretion of bile salt sulfates in bile without inducing cholestasis $(5,6)$. The exact mechanism of estrogen enhancement of bile salt sulfotransferase I synthesis is still under investigation.

The physiologic significance of the 3 -fold greater hepatic bile salt sulfotransferase activity in females because of estrogen induction of the sulfotransferase I isoenzyme may be related to sex-related differences in bile acid metabolism in the rat. The concentration of chenodeoxycholate and lithocholate in serum and bile, as well as the total pool of these potentially hepatotoxic bile acids, is greater in female compared with male rats $(39,40)$. The male rat has greater $6 \beta$-hydroxylase activity than females and converts chenodeoxycholate and lithocholate to muricholic acid (41). This would support the hypothesis that differences in bile salt hydroxylation versus sulfation capacities between sexes result in different predominant mechanisms to protect the liver from the accumulation of potentially hepatotoxic bile acids such as chenodeoxycholate and lithocholate. It thus appears that the induction of bile salt sulfotransferase I activity by estrogen is part of the complex influence of gonadal hormones on the metabolic activity of a number of hepatic enzymes resulting in marked sexrelated differences in bile acid metabolism in the rat.

\section{REFERENCES}

1. Steihl A, Czygan P, Frohling W, Liersch M, Kommerell B 1977 Sulfation of bile acids. In: Bianchi L, Gerok W, Stickinger K. (eds) Liver and Bile. University Park Press, Baltimore, pp 129-138

2. Watkins JB 1983 Placental transport: bile acid conjugation and sulfation in the fetus. J Pediatr Gastroenterol Nutr 2:363-373

3. Palmer RH 1976 Toxic effects of lithocholate on the liver and biliary tree. In: Taylor W (ed) The Hepatobiliary System. Fundamental and Pathological Mechanism. Plenum Press, New York, pp 227-240

4. Back P, Walter K 1980 Developmental pattern of bile acid metabolism as revealed by bile acids analysis of meconium. Gastroenterology 70:11251129 
5. Silverberg M, Solomon L, Ehrlick JC 1971 The hepatotoxic effects of lithocholic acid in the newborn hamster. Gastroenterology 60:753(abstr)

6. Balisteri WF, Zimmer L, Suchy FJ, Bove KD 1984 Bile salt sulfotransferase: alterations during maturation and non-inducability during substrate ingestion. J Lipid Res 25:228-235

7. McSherry CK, Morissey KP, Swarm RL, May PS, Niemann WH, Glenn F 1976 Chenodeoxycholic acid induced liver injury in pregnant and neonatal baboons. Ann Surg 184:490-499

8. Palmer K, Heywood R 1974 Pathological changes in the rhesus fetus associated with the oral administration of chenodeoxycholic acid. Toxicology 2:239246

9. Javitt NB 1976 Cholestasis in infancy: status report and conceptual approach. Gastroenterology 70:1172-81

10. Chen LJ, Kane B, Bujanover Y, Thaier MM 1982 Development and regulation of bile salt sulfotransferase in rat liver. Biochim Biophys Acta 713:358-364

11. Hammerman KJ, Chen LJ, Corugedo AF, Earnest DL 1978 Sex differences in hepatic sulfation of taurolithocholate in the rat. Gastroenterology 75:10211025

12. Kane RE, Chen LJ, Thaler MM 1984 Regulation of bile salt sulfotransferase isoenzymes by gonadal hormones. Hepatology 4:1195-1199

13. Kirkpatrick RB, Wilderman WM, Killenberg PG 1985 Androgens and estrogens affect hepatic bile acid sulfotransferase in male rats. Am J Physiol 248:G639-642

14. Kirkpatrick RB, Killenberg PG 1980 Effects of ethinyl estradiol on enzymes catalyzing bile acid conjugation and sulfation. J Lipid Res 21:895-901

15. Collins RH, Lack L, Killenberg PG 1987 Rat hepatic bile salt sulfotransferase: enzyme response to androgens and estrogens. Am J Physiol 252:G276-280

16. Collins RH, Lack L, Harman KM, Killenberg PG 1986 Rat hepatic bile acid sulfotransferase: identification of the catalytic polypeptide and evidence of polymeric forms in female rats. Hepatology 6:579-586

17. Chen LJ 1980 A simple method for the assay of bile salt sulfotransferases using glycolithocholate coupled to sepharose. Anal Biochem 105:170-173

18. Lowry OH, Rosenbrough NJ, Farr AL, Randall RJ 1951 Protein measurement with folin phenol reagent. J Biol Chem 193:265-275

19. Samuels LD 1964 Actinomycin and its effects. Influence of an effector pathway for hormonal control. N Engl J Med 271:1252-1258

20. Suhadolnik RJ 1970 Puromycin in Nucleoside Antibiotics. Wiley Interscience, New York, pp 3-50

21. Little JM, Richey JE, Van Thiel DH, Lester R 1977 Taurocholate pool size and distribution in the fetal rat. J Clin Invest 63:1042-1049

22. Belnap WM, Balistreri WF, Suchy FJ, Miller PC 1981 Physiologic cholestasis. II. Serum bile acid levels reflect the development of the enterohepatic circulation in rats. Hepatology 1:613-616

23. Singer SS, Giera D, Johnson J, Sylvester S 1976 Enzymatic sulfation of steroids. 1. The enzymatic basis for the sex differences in cortisol sulfation in rat liver preparations. Endocrinology 98:936-974

24. Maus TP, Pearson RK, Anderson RA, Woodson LC, Reiter C, Weinshilboum RM 1982 Rat phenol sulfotransferase:Assay procedure, developmental changes, and glucocorticoid regulation. Biochem Pharmacol 31:849-856

25. Roy AD, and Chatterjee B 1983 Sexual dimorphism in the liver. Annu Rev Physiol 45:37-50

26. Gustafsson JA, Node A, Norstedt G 1983 Sex steroid induced changes in hepatic enzymes. Annu Rev Physiol 45:51-60

27. Bjorkhem I, Eriksson H, Gustaffson JA, Karlmar KA, Sternberg A 1972 Steroid hormone metabolism in developing rats. Eur J Biochem 27:318-326

28. Dohler KD, Wuttke W 1976 Circadian fluctuations of serum hormone levels in prepubertal male and female rats. Acta Endocrinol 83:269-279

29. Bjorkhem I, Eriksson H, Gustafsson JA, Kablmar KE, Stenberg A 1972 Steroid hormone metabolism in developing rats. Eur J Biochem 27:318-326

30. Kirkpatrick, RB, Wilderman NM, Killenberg PG 1985 Androgens and estrogens affect hepatic bile acid sulfotransferase in male rats. Am J Physio 248:G639-642

31. Thomas JA, Mawhinney MG 1973 Estrogen and antiestrogenic drugs. In: Synopsis of Endocrine Pharmacology. University Park Press. Baltimore, pp 95-117

32. Chan L 1982 Hormonal control of gene expression. In: Arias IM, Popper $\mathbf{H}$ Schackter D, Shafritz DA (eds) The Liver: Biology and Pathobiology. Raven Press, New York, pp 169-184

33. Sherman MR, Stevern J 1984 Structure of mammalian steroid receptors: Evolving concepts and methodological development. Annu Rev Physiol 46:83-105

34. Kreek MJ 1969 Cholestasis of pregnancy and during ethinyl estradiol administration in the human and rat. In: Sahlanick HA, Kipnis DM, Wiele RV (eds) Metabolic Effects of Gonadal Hormones and Contraceptive Steroids. Plenum, New York, pp 40-58

35. Gumucio JJ, Valdivieso VD 1971 Studies of the mechanism of the ethiny estradiol impairment of bile flow and bile salt excretion in the rat Gastroenterology 61:339-344

36. Davis RA, Kern F 1976 Effects of ethinyl estradiol and phenobarbital on bile acid synthesis and biliary bile acid formation and cholesterol excretion. Gastroenterology 70:1130-1135

37. Davis RA, Kern F, Showalter R, Sutherland E, Sinensky M, Simon FR 1978 Alteration of hepatic $\mathrm{Na}^{+}, \mathrm{K}^{+}$ATPase and bile flow by estrogen: effects on the liver surface membrane lipid structure and function. Proc Natl Acad Sci USA 75:4130-4134

38. Goldsmith MA, Huling S, Jones AL 1983 Hepatic handling of bile salts and protein in the rat during intrahepatic cholestasis. Gastroenterology 84:97886

39. Yousef IM, Kakis G, Fisher MM 1972 Bile acid metabolism in mammals. II Sex difference in bile acid composition of rat bile. Can J Biochem 50:402408

40. Eyssen H, Smets L, Parmentier G, Janssen G 1977 Sex linked differences in bile acid metabolism of germfree rats. Life Sci 21:702-712

41. Bjorkhem I, Danielsson H, Wikvall K 1974 Hydroxylation of bile acids by reconstituted systems from rat liver microsomes. J Biol Chem 20:6439-6445 